\title{
PemanfaAtan Arcgis Online Sebagai Media Penyampaian Informasi Spasial Kota MaLANG
}

\author{
ARCGis OnLINE Utilization as Media Submission OF THE SPATIAL INFORMATION IN MALANG
}

\author{
${ }^{1}$ Akhmad Faruq Hamdani, ${ }^{2}$ Achmad Maulana Malik Jamil \\ ${ }^{1,2}$ Program Studi Pendidikan Geografi Universitas Kanjuruhan Malang Jl. S. Supriadi 48 Malang \\ E-mail: ${ }^{1}$ hamdani_af@ymail.com, ${ }^{2}$ maulana3188@gmail.com
}

\begin{abstract}
Development of technology has encouraged the delivery of information to be more interactive. Technology is the provision of spatial information via ArcGIS Online. ArcGIS Online is a geographic information system based on Web developed by ESRI to use, create, analyze, and share maps. ArcGIS Online can be used to present the spatial data Malang. The results of the analysis in the form of presentation of spatial information Malang in the shape of an interactive map that contains a general overview of Malang, geographical conditions, and social conditions of Malang through a feature story map in ArcGIS Online.
\end{abstract}

Keywords: Information, Spatial, Malang City ArcGIS Online.

\begin{abstract}
Abstrak. Perkembangan teknologi telah mendorong penyampaian informasi menjadi lebih interaktif. Salah satu pemanfaatan teknologi adalah penyampaian informasi spasial melalui ArcGIS Online. ArcGIS Online adalah sistem informasi geografi yang berbasis Web yang dikembangkan oleh ESRI untuk menggunakan, membuat, menganalisis, dan berbagi peta. Salah satu pemanfaatan ArcGIS Online adalah dapat digunakan untuk menyajikan data spasial Kota Malang. Hasil analisis berupa penyajian informasi spasial Kota Malang dalam bentuk peta interaktif yang berisi tentang gambaran umum Kota Malang, kondisi geografis kota malang, dan kondisi sosial Kota Malang melalui fitur story map yang ada di ArcGIS Online.
\end{abstract}

Kata kunci: Infromasi, Spasial, Kota Malang, ArcGIS Online.

\section{Pendahuluan}

Secara umum ada dua jenis data yang dapat mempresentasikan fenomena dunia nyata. Pertama, data yang merepresentasikan data keruangan (spasial) berisi data posisi, koordinat, ruang atau spasial. Kedua, data yang menjelaskan aspek deskriptif dari kenampakan di permukaan bumi, yang disebut sebagai data non spasial atau atributnya (Prahasta, E., 2014). Informasi spasial merupakan data yang menunjukan posisi suatu wilayah dan penyajian data spasial merupakan salah satu hal penting dalam proses sistem informasi geografi.

Sistem Informasi Geografi (SIG) merupakan sistem informasi yang dirancang untuk mengelola, menganalisa, dan memetakan informasi yang bereferensi geografis berikut atributnya. SIG juga merupakan alat untuk membuat peta, menganalisis data, serta melaporkan hasilnya (ESRI, 2010). SIG ada atas kebutuhan pengelolaan data keruangan (spasial) agar menjadi lebih efisien dan efektif. Teknologi SIG terus berkembang dan mengalami perbaikan seiiring dengan semakin banyaknya pihak yang membutuhkan dan meanfaatkannya.

SIG yang berada pada pertengahan revolusi sistem informasi. Geografi data atau lebih banyak dikenal dengan data spasial sekarang dapat didaptakan dari beberapa teknologi penentuan lokasi, seperti data GPS, sensor jaringan, dan sistem penginderaan jauh (Jhummarwala, et al., 2014). Melalui SIG proses perorganisasian, pengelolaan, 
dan memodifikasi data lebih mudah dilakukan. SIG menangkap persebaran fenomena spasial yang terjadi di muka bumi (Zhu, X., 2014)

Fungsi nyata SIG dapat dideskripsikan menjadi tiga fungsi utama. Pertama, fungsi merepresentasikan secara spasial gambaran permukaan bumi. Fungsi ini menjadi fungsi paling sederhana dan paling dasar dari adanya sistem informasi geografi. Peta digital ini memberikan gambaran lokasi geografi serta penjelaskan atribut yang ada di lokasi tersebeut. Kedua, fungsi pengelolaan data spasial. Pengelolaan data spasial dalam bentuk layer peta digital yang memiliki beberapa tema tertentu. Pengelolaan data spasial dapat disesuaikan berdasarkan kebutuhan pengguna data. Ketiga, fungsi analisis spasial dan permodelan. Fungsi ini berdasarkan lokasi objek yang telah dianalisis, kemampuan mensimulasikan beberapa data spasial dengan data atribut sangat berguna dalam perencanaan strategis suatu wilayah (Zhu, X., 2014).

Sistem informasi geografi sebagai sistem pengumpul data spasial terus mengalami perkembangan seiring berjalannya waktu. Generasi pertama dari SIG dikenal sebagai SIG model Desktop terus berkembang menjadi SIG dengan model Web (Jhummarwala, et al., 2014). ArcGIS Online adalah sistem informasi geografi yang berbasis Web yang dikembangkan oleh Environmental Systems Research Institute (ESRI) dan merupakan bagian dari sistem ArcGIS . ArcGIS Online merupakan web kolaboratif yang memungkinkan untuk menggunakan, membuat, menganalisis, dan berbagi peta. Hal ini karena ArcGIS Online merupakan bagian dari sistem ArcGIS Desktop, ArcGIS for Desktop, ArcGIS Server, ArcGIS Web APIs, dan ArcGIS Runtime SDKs.

Salah satu pemanfaatan ArcGIS Online adalah dapat digunakan untuk mempresentasikan data spasial Kota Malang. Kota Malang merupakan salah satu kota terbesar di Provinsi Jawa Timur. Secara astronomis Kota Malang terletak pada posisi $112,06^{0}-112,07^{0} \mathrm{BT}$ dan $7,06^{0}-8,07^{0} \mathrm{LS}$, dengan luas wilayah sebesar $110,06 \mathrm{~km}^{2}$ yang terbagi menjadi lima kecamatan, yakni Kecamatan Kedungkandang, Klojen, Sukun, Blimbing, dan Lowokwaru (BPS, 2016). Kota Malang sebagai salah satu kota di Jawa Timur perlu memberikan informasi tentang perkembangan yang ada di Kota Malang. Oleh karenanya pemanfaatan ArcGIS online sebagai media penyampaian infomasi spasial Kota Malang menjadi hal yang penting.

\section{Metode Penelitian}

Pendekatan penelitian ini bersifat kuantitatif deskriptif. Tujuan penelitian ini adalah untuk untuk dapat mendeskripsikan, menginterpretasikan, dan menyampaikan informasi spasial tentang Kota Malang dalam bentuk peta interaktif dengan memanfaatkan ArcGIS Online. Basis data yang dikumpulkan terdiri dari dua jenis data, yakni:

[1]. Basis data spasial, yang berupa peta Kota Malang.

[2]. Basis data atribut, yang berupa data kondisi geografis serta data sosial berdasarkan hasil survey lapangan dan data sekunder dari malang dalam angka tahun 20152016.

Tahapan yang dilakukan dalam penelitian ini yakni:

[1]. Tahapan awal dimulai dari pengumpulan informasi spasial Kota Malang, baik data spasial maupun data atribut.

[2]. Tahapan pengolahan data spasial dan non-spasial dengan perangkat lunak ArcGIS Desktop 10.4.

[3]. Tahapan mengunggah data ke situs ArcGIS Online 
[4]. Tahapan pembuatan penyajian peta interaktif dengan memanfaatkan fitur Story Map yang ada di situs ArcGIS Online.

[5]. Tahapan menyajikan informasi spasial Kota Malang melalui ArcGIS Online

\section{Hasil dan Pembahasan}

Hasil analisis berupa penyajian informasi spasial Kota Malang dalam bentuk peta interaktif yang berisi tentang gambaran umum Kota Malang, kondisi geografis kota Malang, dan kondisi sosial Kota Malang. Hasil dari sistem informasi geografi menggunakan ArcGIS Online memudahkan pengguna data untuk melihat lokasi beserta kondisi geografis dan kondisi sosial yang ada di dalamnya. Gambar 1 menampilkan informasi umum tentang Kota Malang yang berisi kondisi sosial, yakni: jumlah penduduk kota malang (851.298 jiwa), kepadatan penduduk (7735 jiwa/ $\left./ \mathrm{km}^{2}\right)$, perbandingan jenis kelamin/sex ratio (97), laju pertumbuhan penduduk $(0,63)$. Sedangkan, kondisi geografi yang ditampilkan adalah batas wilayah Kota Malang, kondisi iklim yang berdasarkan dari klasifikasi iklim koppen (iklim tropis hutan musim/aw), iklim schmidt-fergusson (iklim agak kering/ tipe d), iklim mohr (tipe iklim agak kering/golongan III), dan rata-rata curah hujan Kota Malang (164 mm/bulan).

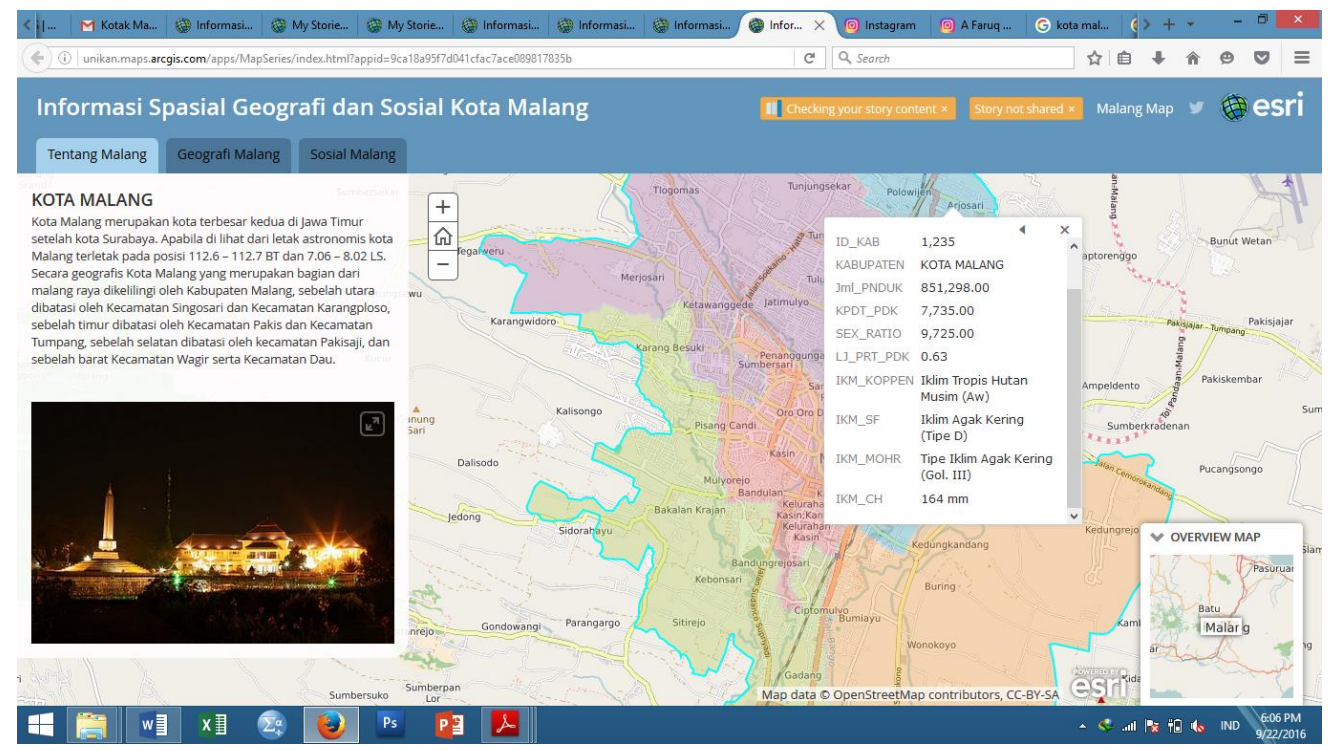

Gambar 1. Tampilan ArcGIS Online menggunakan fitur story map

Pada gambar 1 menggunakan Base Map dengan tampilan Open Street Map. Tampilan open street map digunakan untuk memberikan kenampakan jalan beserta nama kelurahan yang ada di setiap kecamatan yang berada di Kota Malang. Kecamatan Blimbing dengan sebelas kelurahan (Jodipan, Polehan, Kesatrian, Bunulrejo, Purwantoro, Pandanwangi, Blimbing, Purwodadi, Polowijen, Arjosari, dan Balearjosari), Kecamatan Kedungkandang dengan dua belas kelurahan (Arjowinangun, Tlogowaru, Wonokoyo, Bumiayu, Buring, Mergosono, Kotalama, Kedungkandang, Sawojajar, Madyopuro, Lesanpuro, dan Cemorokandang), Kecamatan Klojen dengan sebelas kelurahan (Kasin, Sukoharjo, Kiduldalem, Kauman, Bareng, Gadingkasri, Orooro dowo, Klojen, Rampal Celaket, Samaan, dan Penanggungan), Kecamatan Lowokwaru dengan dua belas kelurahan (Merjosari, Dinoyo, Sumbersari, Ketawanggede, Jatimulyo, Lowokwaru, Tulusrejo, Mojolangu, Tunjungsekar, Tasikmadu, Tunggulwulung, dan Tlogomas), dan Kecamatan Sukun dengan sebelas 
kelurahan (Bakalan Krajan, Gadang, Ciptomulyo, Bandung Rejosari, Mulyorejo, Bandulan, Tanjungrejo, Sukun, Pisang Candi, dan Karang Besuki).

\section{Geografi Kota Malang}

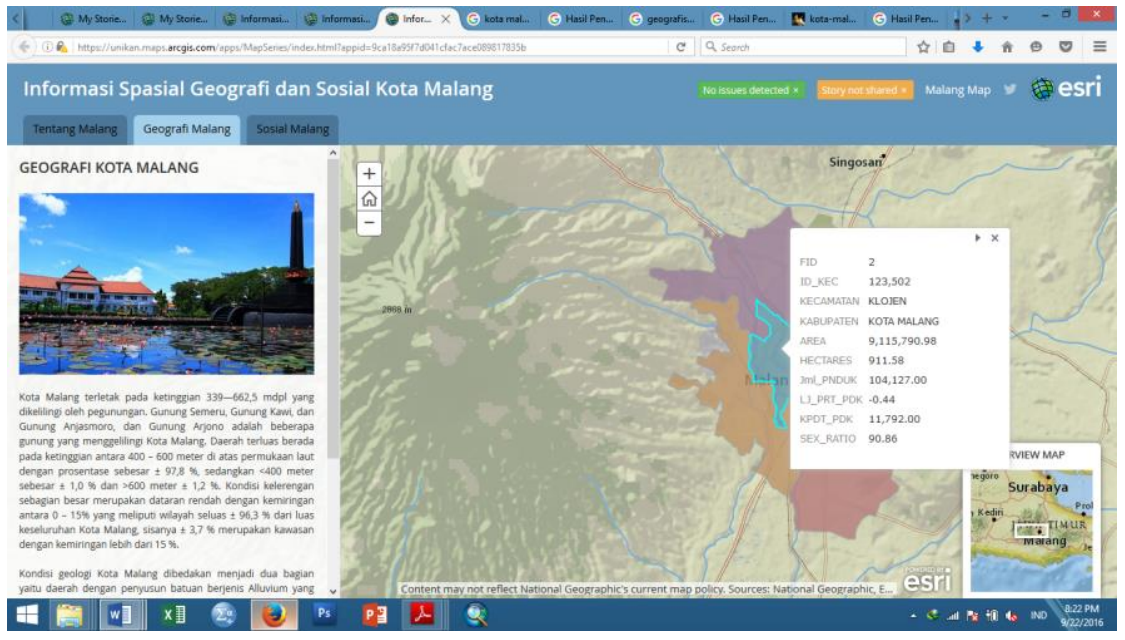

Gambar 2. Tampilan ArcGIS Online Informasi Geografi Kota Malang

Informasi Geografi Kota Malang seperti yang disajikan pada gambar 2 menampilkan peta Kota Malang beserta atribut berupa penjelasasan kondisi geografi kota malang. Pada gambar 2 menggunakan Base Map dengan tampilan National Geographic. Tampilan National Geographic dipilih karena agar para pembaca lebih mudah untuk melihat kondisi geografi, baik di Kota Malang ataupun wilayah lain disekitar Kota Malang. Kota Malang yang pada ketinggian 339-662,5 mdpl dikelilingi oleh wilayah pegunungan. Gunung Semeru, Gunung Kawi, Gunung Anjasmoro, dan Gunung Arjono adalah beberapa gunung yang menggelilingi Kota Malang. Sebagian besar wilayah Kota Malang merupakan wilayah dataran, dibuktikan dengan tampilan yang ada pada gambar 2 .

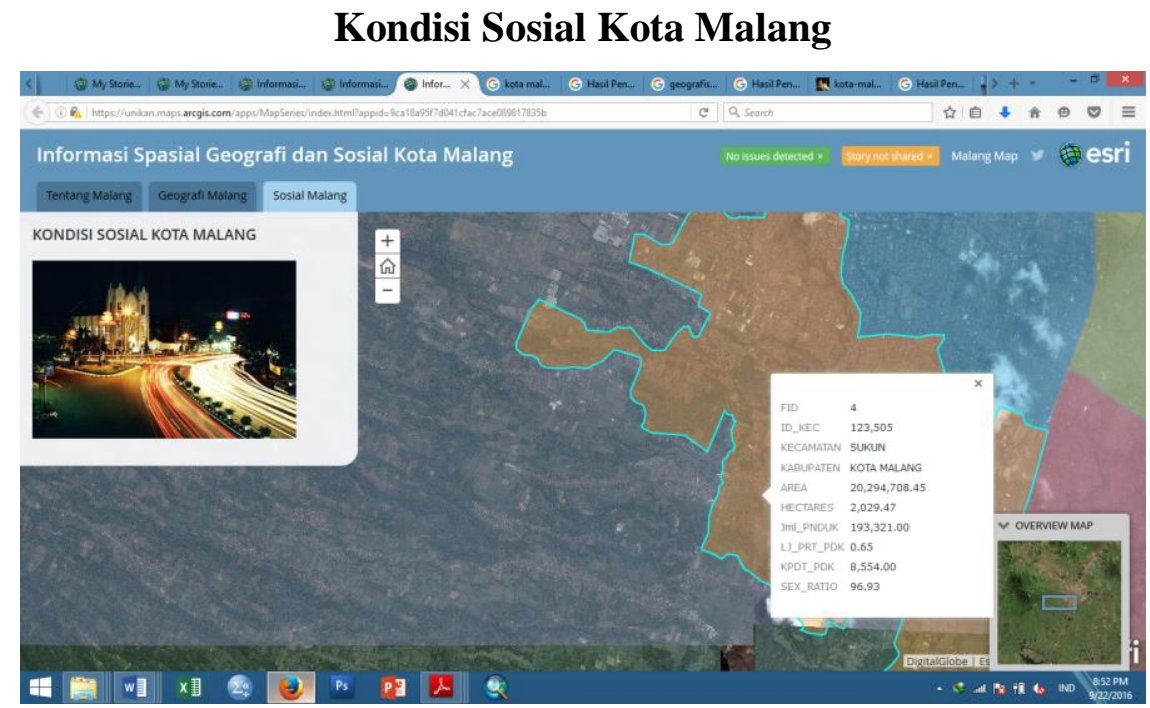

Gambar 3. Tampilan ArcGIS Online Informasi Sosial Kota Malang

Informasi sosial yang disajikan dalam ArcGIS Online menggunakan base map dengan tampilan Imagery With Label. Base map tersebut dipilih karena menampilkan kondisi geografi dengan perbandingan luas lahan terbangun dengan lahan tertutup, 
sehingga dapat dilihat kondisi lahan terbangun yang dimanfaatkan oleh warga Kota Malang. Disamping itu dalam informasi spasial juga dipaparkan data tentang kependudukan, yang mencakup jumlah penduduk, laju pertumbuhan penduduk, kepadatan penduduk, dan perbandingan jenis kelamin (sex ratio) di setiap kelurahan

\section{Kesimpulan}

Berdasarkan hasil penelitian pemanfaatan ArcGIS online sebagai media penyampaian informasi spasial kota malang dapat ditarik kesimpulan sebagai berikut: Hasil dari sistem informasi geografi menggunakan ArcGIS Online memudahkan pengguna data untuk melihat lokasi beserta kondisi geografis dan kondisi sosial yang ada di dalam wilayah tersebut termasuk didalamnya berupa jumlah penduduk, kepadatan penduduk, perbandingan jenis kelamin/sex ratio, laju pertumbuhan penduduk. Sedangkan, kondisi geografi yang ditampilkan adalah batas wilayah Kota Malang, kondisi iklim yang berdasarkan dari klasifikasi iklim koppen, iklim schmidtfergusson, iklim mohr, dan rata-rata curah hujan Kota Malang. Pembaruan data atribut maupun data spasial pada peta kota Malang ini dapat dilakukan dengan dua cara yaitu: melakukan pembaharuan menggunakan perangkat lunak pengolah data spasial seperti ArcGIS Desktop lalu mengunggah ulang datanya ke akun ArcGIS Online atau dapat melakukan pembaharuan data langsung pada situs ArcGIS Online.

\section{Ucapan Terima Kasih}

\section{Daftar pustaka}

BPS. (2015). Kota Malang Dalam Angka 2015. Malang: Badan Pusat Statistik.

BPS. (2016). Kota Malang Dalam Angka 2016. Malang: Badan Pusat Statistik.

ESRI. (2012). Quick Start Guide To ArcGIS Online. New York: ESRI.

Jhummarwala, A., M.B. Pothdar, dan Prashant, C. (2014). Parallel and Distributed GIS

for Processing Geo-Data: An Overview. International Journal of Computer Applications (0975-8887). Volume 106- No 16 November 2014.

Prahasta, E. (2014). Sistem Informasi Geografi (Konsep-Konsep Dasar Perspektif Geodesi dan Geomatika). Bandung: Infromatika.

Zhu, X. (2014). GIS and Urban Mining. Resources Journal. 3 Maret 2014. 